\section{Sorption of selected radionuclides \\ from liquid radioactive waste \\ by sorbents of biological origin: The alkaline earth alginates}

Leon Fuks (D), Agata Oszczak-Nowińska

\begin{abstract}
The sorption of ${ }^{241} \mathrm{Am}^{3+},{ }^{85} \mathrm{Sr}^{2+}$ and ${ }^{137} \mathrm{Cs}^{+}$by calcium, strontium and barium alginates has been studied under different operation conditions. The most prominent adsorption was found in the pH range of 5-6 for all systems, even if the observed dependence on the acidity of the solution was small. The most favourable time for the adsorption process was found to be about $2 \mathrm{~h}$ for calcium alginate and $4 \mathrm{~h}$ for the other two sorbents.
\end{abstract}

Keywords: Alginates $\bullet$ Biosorption $\bullet$ Radionuclides $\bullet$ Caesium $\bullet$ Strontium $\bullet$ Americium

Leon Fuks ${ }^{\bowtie}$

Institute of Nuclear Chemistry and Technology

Dorodna 16 Str., 03-195 Warszawa, Poland

E-mail: 1.fuks@ichtj.waw.pl

Agata Oszczak-Nowińska ${ }^{\bowtie}$

Military University of Technology

Institute of Chemistry

Kaliskiego 2 Str., 00-908 Warszawa, Poland

E-mail: agata.oszczak@wat.edu.pl

Received: 21 December 2020

Accepted: 12 February 2021

\section{Introduction}

Introduction of the so-called green chemistry in 1990 had a great impact on all other fields of experimental science, including radiochemistry and nuclear technology. The observed development of radiochemical separation methods requires the intense use of solvents and reagents that form large amounts of unnecessary sludge. Thus, several environmentally friendly extractants, sorbents and solvents have recently been proposed. However, for economic reasons, the replacement of chemicals used in existing separation methods and radioactive waste disposal technologies with the novel, green reagents is still slow.

One of the most effective methods of eliminating radioactive metals from wastewater is biosorption, a process that uses materials of biological origin (biosorbents). Low costs, easy regeneration of the biosorbent and the possibility of metal recovery are among the major advantages of biosorption compared with conventional treatment $[1,2]$. Biosorption is a physico-chemical process consisting of absorption, adsorption, ion exchange, surface complexation and sometimes precipitation, although not all of these processes are always in use simultaneously. Biosorbents can be organic or inorganic materials and are necessarily water-insoluble. They can be either living or dead biomass ${ }^{1)}$, as well as

\footnotetext{
1) According to the definition provided in the Regulation of the Polish Minister of Economy in 2006, biomass is "solid or liquid substances of plant or animal origin that are biodegradable, derived from products, waste and residues from agricultural and forestry production, as well as from industry processing their products, as well as the part of the remaining waste that is biodegradable" [3].
}

0029-5922 (c) 2021 The Author(s). Published by the Institute of Nuclear Chemistry and Technology.

This is an open access article under the CC BY-NC-ND 4.0 licence (http://creativecommons.org/licences/by-nc-nd/4.0/). 
excreted products or products obtained by industrial processing or in the laboratory from the biomass. Sorbing materials may be tailored to fix specific pollutants in wastewater $[4,5]$.

Alginates are among the most common biosorbents currently used for radioactive metal-bearing aqueous streams. They are biopolymers of alginic acid, extracted from different types of algae, mainly green but also brown organisms. Calcium alginate has already been found to exhibit a relatively high uptake rate and distribution coefficient of ${ }^{90} \mathrm{Sr}^{2+}[6]$ and ${ }^{241} \mathrm{Am}^{3+}$ ions $[4,7]$. However, separation of the metal-loaded sorbent from the purified solution is often a problem, and the use of magnetic alginate sorbents has thus received significant attention in recent years as a means of solving this technical problem [4].

Large amounts of radioactive aqueous waste that contains long-life, low-active radionuclides, such as ${ }^{60} \mathrm{Co}$ (half-life $\left(t_{1 / 2}\right)$ of 15.3 years), ${ }^{90} \mathrm{Sr}$ (30.2 years) and ${ }^{137} \mathrm{Cs}$ (28.8 years) are mainly produced by nuclear power plant (NPP) installations. Additionally, nuclear medicine and scientific laboratories generate liquid waste that may also contain other radionuclides: ${ }^{241} \mathrm{Am}\left(t_{1 / 2}=432.2\right.$ years $),{ }^{192} \operatorname{Ir}(73.8$ days $),{ }^{125} \mathrm{I}$ (59.6 days), ${ }^{103} \mathrm{Pd}$ (17.0 days) or ${ }^{106} \mathrm{Ru}$ (1.02 years). The composition of the novel wastes varies unpredictably and changes during storage due to the decay of the radionuclides. Moreover, data on the radionuclide content of liquid wastes are not usually published in commonly available sources. Solutions should be concentrated and solidified before final disposal [8]. Such radionuclides are also of great concern especially when a NPP fails and pollutes the environment, as well as the potable water (e.g., the Chernobyl or Fukushima catastrophes) [9].

The main objective of this work was to study the alginate spherical gels formed by three alkaline earth metals (calcium, strontium and barium) as potential sorbents in the processing of radioactive liquid wastes, either to remove the radionuclides from the contaminated aqueous solutions or to protect the environment from their release. Specifically, the sorption of ${ }^{241} \mathrm{Am}^{3+},{ }^{85} \mathrm{Sr}^{2+}$ and ${ }^{137} \mathrm{Cs}^{+}$from diluted aqueous solutions was studied. The radionuclides studied are the three most abundant radionuclides in Polish radioactive waste [10].

\section{Experimental}

Analytical grade chemicals (Sigma-Aldrich or Avantor (earlier, POCh), both Polish branches) and deionized water were used. The radiotracers $\left({ }^{137} \mathrm{Cs}\right.$, ${ }^{85} \mathrm{Sr}$ and ${ }^{241} \mathrm{Am}$ ) were purchased as acidic aqueous solutions from Polatom (the National Centre for Nuclear Research, Świerk, Poland).

Working solutions that contained all the studied radionuclides (ca. $10^{-6} \mathrm{M}$, each) were made gravimetrically by adding the necessary amounts of standard solutions in $10^{-3} \mathrm{M}$ nitric acid and were examined for radiochemical purity by $\gamma$-spectrometry.

Spherical $\mathrm{Ca}^{2+}, \mathrm{Sr}^{2+}$ and $\mathrm{Ba}^{2+}$ alginate sorbents were prepared according to the procedure already described [6]: $0.5 \mathrm{M}$ aqueous solution of the alkaline earth chloride (one, in any synthesis) was dropped into a continuously stirred $2 \% \mathrm{w} / \mathrm{w}$ aqueous solution of sodium alginate. The reaction was carried out at ambient temperature. The sorbent, obtained in the form of granules of ca. $3 \mathrm{~mm}$ diameter, was kept in the mother liquid for a further $24 \mathrm{~h}$. The sorbent was then transferred into a solution containing $0.01 \mathrm{M} \mathrm{KCl}$ and $0.001 \mathrm{M} \mathrm{CaCl}_{2}$ and kept for a maximum of two weeks for the experiments. Before starting any experiment, the sorbent was carefully washed with bi-distilled water.

The adsorption properties of the alginates towards micro amounts $\left(10^{-8}-10^{-9} \mathrm{~mol} \cdot \mathrm{dm}^{-3}\right)$ of four radionuclides of $\mathrm{Cs}^{+}, \mathrm{Sr}^{2+}$ and $\mathrm{Am}^{3+}$ were investigated in batch experiments. A weighed amount of the sorbent $(100 \mathrm{mg})$ was agitated (speed: $400 \mathrm{rpm}$; ambient temperature of ca. $21 \pm 1^{\circ} \mathrm{C}$ ) with $3 \mathrm{~mL}$ of any solution containing all the radionuclides studied. After the required phase contact time, samples were withdrawn from the shaker and left for the phases' separation. The supernatant was then confectioned into $1 \mathrm{~mL}$ portions and the equilibrium radionuclide concentrations were determined by measuring their radiation activity concentrations. All radioactivity measurements were performed in the well-type geometry. Each experiment was performed in triplicate, and the radiation activity of each sample was also measured three times.

Values of the distribution ratio $\left(K_{d}\right)$, i.e. the normalized ratio of the radioactivity concentration in the equilibrium solid phase to the initial radioactivity concentration in the purified solution, were calculated using Eq. (1):

$$
K_{d}=\frac{A_{\text {solid }}}{A_{0}} \cdot \frac{V}{m}=\frac{A_{0}-A_{\mathrm{eq}}}{A_{0}} \cdot \frac{V}{m}
$$

where: $A_{0}$ and $A_{\text {eq }}$ denote the specific activity of the initial and equilibrium solutions, respectively, $\left(\mathrm{cpm} \cdot \mathrm{mL}^{-1}\right) ; A_{\text {solid }}$ denotes the radiation activity of the absorbed radionuclide $\left(\mathrm{cpm} \cdot \mathrm{mg}^{-1}\right)$, calculated as the difference between the values measured for the initial and equilibrium solutions; $V$ is the volume of the solution (mL); and $m$ is the mass of the sorbent (mg).

In extension to the sorption studies, the desorption of radionuclides $\mathrm{Cs}^{+}, \mathrm{Sr}^{2+}$ and $\mathrm{Am}^{3+}$ was also examined from all spherical alginate sorbents loaded with a mixture of radionuclides. For this purpose, water, $0.01 \mathrm{M} \mathrm{HCl}, 0.01 \mathrm{M} \mathrm{NaNO}_{3}, 0.01 \mathrm{M} \mathrm{NaHCO}_{3}$ and $0.01 \mathrm{M} \mathrm{Na}_{2} \mathrm{SO}_{4}$ solutions were used as the desorbing media. All experiments were carried out under the following conditions:

- shaking time: $4 \mathrm{~h}$,

- shaking temperature: $21 \pm 1^{\circ} \mathrm{C}$,

- mass of the radionuclide saturated sorbent: $0.1 \mathrm{~g}$,

- volume of the desorbing solution: $3 \mathrm{~mL}$,

- phase separation time (no rotation): $24 \mathrm{~h}$.

\section{Results and discussion}

In this work, the sorption of micro concentrations $\left(10^{-8}-10^{-9} \mathrm{M}\right)$ of $\mathrm{Cs}^{+}, \mathrm{Sr}^{2+}$ and $\mathrm{Am}^{3+}$ by the alginate sorbents was studied to check their ability to decontaminate aqueous solutions and store radionuclides 
in the solid phase. Three alkaline earth cations (calcium, strontium and barium) were analysed as gelling agents for sodium alginate.

For establishing the potential decontamination procedure, the main parameters tested were the effect of contact time on the sorption of the radionuclides, the effect of $\mathrm{pH}$, the effect of the mass of metal sorbed and the efficiency of desorption of the radionuclides from the metal loaded sorbent.

\section{Effect of contact time on sorption of the radionuclides}

Results for the rate of $\mathrm{Am}^{3+}$ adsorption as a function of agitating time for all alginate sorbents are given in Fig. 1a. For the calcium alginate, after a shaking time of $120 \mathrm{~min}$, no more metal was adsorbed. In the case of strontium and barium alginates, a plateau of $\mathrm{Am}^{3+}$ uptake is reached within $180 \mathrm{~min}$. As seen in Fig. 1b, the adsorption plateau of $\mathrm{Cs}^{+}$, $\mathrm{Sr}^{2+}$ and $\mathrm{Am}^{3+}$ by calcium alginate ( $\left.\mathrm{pH} 5\right)$ is reached at about the same time, at $120 \mathrm{~min}$. The values of the distribution ratio are $2.1 \times 10^{4}, 5.4 \times 10^{3}$ and $5.5 \times 10^{2}$, respectively.

Values of the americium distribution ratio $\left(K_{d}\right)$ were found to be $2.1 \times 10^{4}, 1.1 \times 10^{4}$ and $1.6 \times 10^{4}$, respectively. This means that about $98 \%$ of $\mathrm{Am}^{3+}$ may be removed by sorption with calcium alginate,
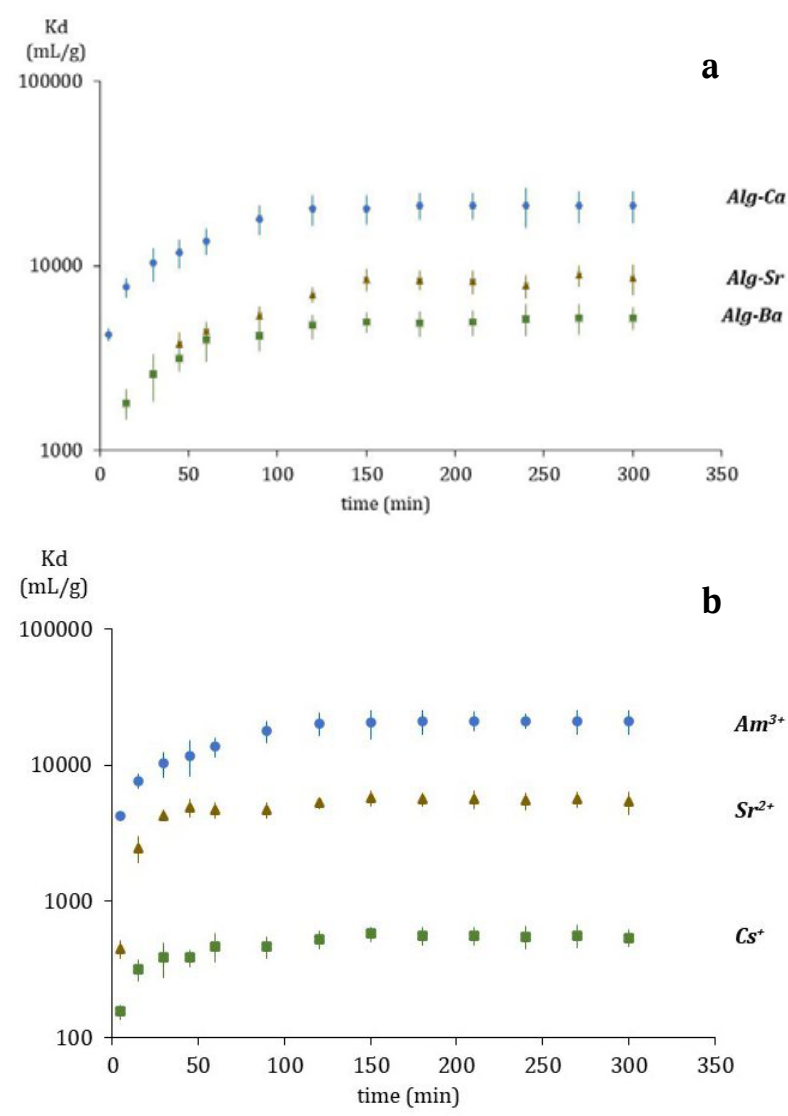

Fig. 1. (a) Effect of contact time on the sorption of micro amounts of ${ }^{241} \mathrm{Am}^{3+}$ onto calcium, strontium and barium alginate biosorbents. (b) Adsorption of micro amounts of $\mathrm{Cs}^{+}, \mathrm{Sr}^{2+}$ and $\mathrm{Am}^{3+}$ onto calcium alginate $(\mathrm{pH} 5$ and room temperature). while the uptakes of $80 \%$ and $70 \%$ were obtained for strontium- and barium alginates, respectively. Furthermore, it was found that $\mathrm{Sr}^{2+}$ radionuclide may be removed from aqueous solutions using the calcium, strontium and barium alginate with an efficiency of $86 \%, 85 \%$ and $81 \%$, respectively. In turn, only about $5-10 \%$ of $\mathrm{Cs}^{+}$ions are removed by any alginate.

\section{Effect of $\mathrm{pH}$ on the sorption of micro amounts of the radionuclides}

The acidity of the decontaminated solution is among the most significant factors determining the solution chemistry of metals, i.e. pH-dependent metal hydrolysis and speciation, complexation or redox reactions influence the potency of the sorption of metals. In addition, acidity reflects the behaviour of the adsorption sites of the sorbent (dissociation, protonation, etc.).

The dependence of the distribution ratio values of $\mathrm{Am}^{3+}$ on the initial $\mathrm{pH}$ of the solution is shown in Fig. 2a. The most favourable $\mathrm{pH}$ value was found to be around 5-6. One can imagine that, at sufficiently low $\mathrm{pH}$ values, the binding sites of the adsorbent also interact with hydronium ions, which compete with metal ions and decrease the metal ion interaction with the binding sites of the sorbent. As the $\mathrm{pH}$ increases, the charge of the binding sites becomes more negative, which promotes the adsorption of the metals. After pH 5-6, the amount of different americium hydroxy- and carbonate forms starts to
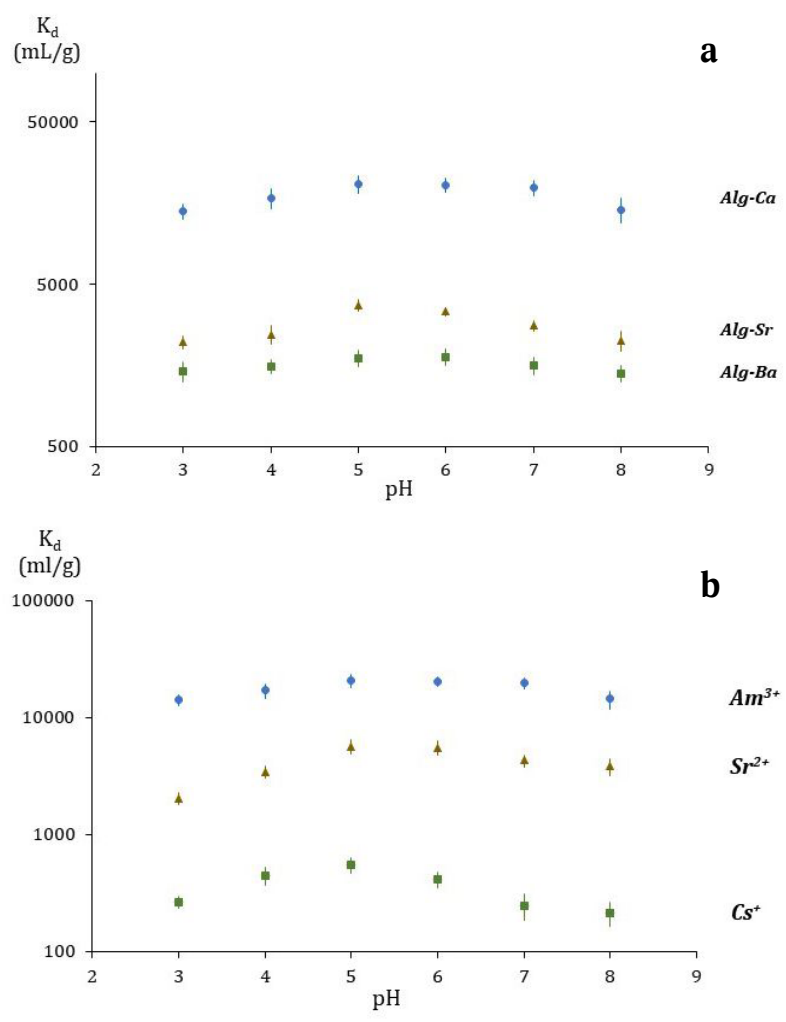

Fig. 2. (a) Adsorption of micro amounts of ${ }^{241} \mathrm{Am}^{3+}$ onto calcium, strontium and barium alginate biosorbents vs. $\mathrm{pH}$ of the initial solution. (b) Adsorption of micro amounts of $\mathrm{Cs}^{+}, \mathrm{Sr}^{2+}$ and $\mathrm{Am}^{3+}$ onto calcium alginate (room temperature, contact time of the phases: $300 \mathrm{~min}$ ). 


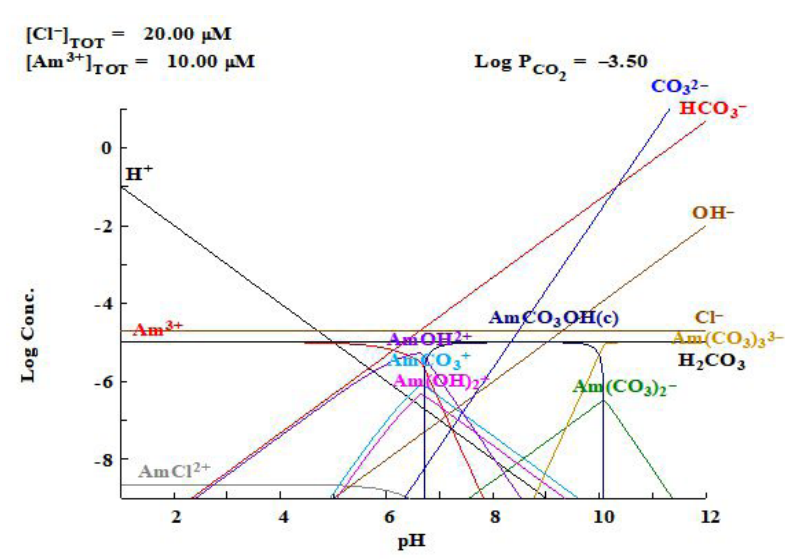

Fig. 3. $\mathrm{Am}^{3+}$ complexes in aqueous solutions of different pH. Simulation computed using the Medusa program [11].

play a significant role (see Fig. 3), which decreases the sorption efficiency. In our study, at around $\mathrm{pH}$ 5 , an interplay of the different forms of americium cations, dissociation of the carboxyl groups of the polyuronic chain and concurrent sorption of the hydronium ions creates the most favourable conditions for metal sorption. The same can be stated for the sorption of $\mathrm{Sr}^{2+}$ and $\mathrm{Cs}^{+}$ions.

Figure $2 \mathrm{~b}$ shows that, independent of the studied metal, the most favourable conditions for sorption by the alginates is an aqueous solution $\mathrm{pH}$ of around 5-6.

\section{Equilibrium isotherms}

To determine the relationship between the mass of metal sorbed in the equilibrium conditions and its initial concentration in the solution, different models (called sorption isotherms) have been proposed [12, 13]. Three of the most commonly used models for the description of the biosorption process are those of Freundlich, Langmuir and Dubinin-Radushkevich. As the solutions are extremely diluted $\left(10^{-8}\right.$ $10^{-9} \mathrm{M}$ ), the interaction between metal cations may be neglected, and the single-component models seem to be reasonable.
The Freundlich isotherm, the first empirically formulated adsorption model, describes an imperfect, reversible process of adsorption, which is not limited only to the formation of a monolayer [12] This isotherm can be applied to the adsorption with non-uniform adsorption heat distribution and the adsorbate affinity on the sorbent surface.

The Langmuir adsorption isotherm, formulated empirically, is usually used to measure and compare the adsorbing properties of different sorbents, mainly biosorbents [12]. This model assumes that adsorption is a monolayer process and can only occur in a defined number of identical or equivalent binding sites. According to this model, the adsorbate molecules do not interact mutually, and therefore steric interference does not occur. Thus, the Langmuir isotherm refers to a process in which any molecule possesses the same enthalpy and all binding sites possess a comparable affinity for the adsorbate.

The Dubinin-Radushkevich isotherm is also an empirical model; however, it was proposed for adsorption according to the pore-filling mechanism. As a rule, it is applied to express the process of adsorption occurring either on homogeneous or heterogeneous surfaces. The model is substantially successful in describing the adsorption of high or intermediate sorbate activity, but is unsatisfactory in describing sorption of low concentrated species [12].

To characterize the process of sorption of ${ }^{241} \mathrm{Am}(\mathrm{III}),{ }^{85} \mathrm{Sr}$ (II) and ${ }^{137} \mathrm{Cs}(\mathrm{I})$ on the alginate sorbents, these were all used in their linearized forms. For the sake of clarity of the text, the appropriate equations are not presented; however, they can be found in the papers of Foo or Ayawei, for example $[12,13]$. The concentration of metals, expressed in the radioactivity concentration of the solution arising from each radionuclide $\left(\mathrm{Bq} \cdot \mathrm{cm}^{-3}\right)$, was converted into the SI units $\left(\mathrm{mol} \cdot \mathrm{dm}^{-3}\right)$ before the computation. Consequently, the results obtained in the present work can be compared with the results obtained for other metals found in the literature. The obtained results are presented in Table 1.

Table 1. Parameters of Freundlich, Langmuir and Dubinin-Radushkevich isotherms of $\mathrm{Cs}^{+}, \mathrm{Sr}^{2+}$ and $\mathrm{Am}^{3+}$ sorption on calcium, strontium and barium alginate sorbents ( $\mathrm{pH}$ 5, time: $4 \mathrm{~h}$, temperature: $21 \pm 1^{\circ} \mathrm{C}$ )

\begin{tabular}{|c|c|c|c|c|c|c|c|c|c|c|}
\hline & \multicolumn{3}{|c|}{ Freundlich isotherm } & \multicolumn{3}{|c|}{ Langmuir isotherm } & \multicolumn{4}{|c|}{ Dubinin-Radushkevich isotherm } \\
\hline & $\begin{array}{c}K_{\mathrm{F}} \\
\left(\mathrm{dm}^{3} / \mathrm{mg}\right)\end{array}$ & $1 / \mathrm{n}$ & $R^{2}$ & $a_{\max }$ & $\begin{array}{c}K_{\mathrm{L}} \\
\left(\mathrm{dm}^{3} / \mathrm{mg}\right)\end{array}$ & $R^{2}$ & $\begin{array}{c}X_{m} \\
(\mathrm{mg} / \mathrm{g})\end{array}$ & $\begin{array}{c}B \\
\left(\mathrm{~mol}^{2} / \mathrm{J}^{2}\right)\end{array}$ & $\begin{array}{c}E \\
(\mathrm{~kJ} / \mathrm{mol})\end{array}$ & $R^{2}$ \\
\hline \multicolumn{11}{|c|}{ Calcium alginate } \\
\hline Am(III) & $2.87 \times 10^{-5}$ & 0.97 & 0.99 & $4.46 \times 10^{-3}$ & $8.98 \times 10^{2}$ & 0.80 & 0.02 & $1.41 \times 10^{-4}$ & 7.07 & 1.00 \\
\hline $\operatorname{Sr}(\mathrm{II})$ & $4.68 \times 10^{-7}$ & 1.00 & 1.00 & $2.99 \times 10^{-3}$ & $5.00 \times 10^{2}$ & 0.77 & 0.02 & $1.41 \times 10^{-4}$ & 7.07 & 1.00 \\
\hline $\mathrm{Cs}(\mathrm{I})$ & $1.67 \times 10^{-7}$ & 1.00 & 1.00 & $1.23 \times 10^{-3}$ & $6.23 \times 10^{1}$ & 0.90 & 0.01 & $1.41 \times 10^{-4}$ & 7.07 & 1.00 \\
\hline \multicolumn{11}{|c|}{ Strontium alginate } \\
\hline $\operatorname{Am}(\mathrm{III})$ & $3.54 \times 10^{-8}$ & 1.46 & 0.90 & $6.57 \times 10^{-2}$ & $5.70 \times 10^{2}$ & 0.84 & 0.01 & $1.41 \times 10^{-4}$ & 7.07 & 1.00 \\
\hline $\mathrm{Sr}(\mathrm{II})$ & $2.50 \times 10^{-6}$ & 1.05 & 1.00 & $2.99 \times 10^{-3}$ & $2.27 \times 10^{2}$ & 0.96 & 0.01 & $1.41 \times 10^{-4}$ & 7.07 & 1.00 \\
\hline $\mathrm{Cs}(\mathrm{I})$ & $1.55 \times 10^{-5}$ & 1.00 & 1.00 & $1.31 \times 10^{-2}$ & $6.57 \times 10^{1}$ & 0.84 & 0.02 & $1.41 \times 10^{-4}$ & 7.07 & 1.00 \\
\hline \multicolumn{11}{|c|}{ Barium alginate } \\
\hline Am(III) & $3.17 \times 10^{-6}$ & 1.34 & 0.91 & $6.75 \times 10^{-2}$ & $7.70 \times 10^{2}$ & 0.83 & 0.01 & $1.41 \times 10^{-4}$ & 7.07 & 1.00 \\
\hline $\operatorname{Sr}(\mathrm{II})$ & $7.32 \times 10^{-6}$ & 0.99 & 1.00 & $2.86 \times 10^{-3}$ & $1.47 \times 10^{2}$ & 0.80 & 0.01 & $1.41 \times 10^{-4}$ & 7.07 & 1.00 \\
\hline $\mathrm{Cs}(\mathrm{I})$ & $1.67 \times 10^{-5}$ & 1.00 & 1.00 & $1.30 \times 10^{-2}$ & $6.31 \times 10^{1}$ & 0.83 & 0.02 & $1.41 \times 10^{-4}$ & 7.07 & 1.00 \\
\hline
\end{tabular}


As can be seen from Table 1, the Freundlich approach describes the sorption of $\mathrm{Cs}^{+}$and $\mathrm{Sr}^{2+}$ better for all sorbents compared with the Langmuir model. It can also be seen that the sorption of $\mathrm{Am}^{3+}$ by calcium alginate (but not by strontium and barium alginate) is described best by using the Dubinin-Radushkevich model. However, as mentioned above, this approach fails to describe the sorption results of low concentrated species. The fairly good approximation of the $\mathrm{Am}^{3+}$ sorption by the Freundlich model $\left(R^{2}\right.$ greater than 0.9$)$ suggests that this model may be useful in describing the system in question.

Because of the physico-chemical basis of the Freundlich model, it seems reasonable to conclude that the surface of the sorbent is heterogeneous. It is known that sugar polymeric molecules consist of randomly distributed mannuronic and glucuronic units. As only the latter are involved in the metal bonding process, metal-binding sites are also spread randomly.

In turn, the great dilution of sorbed radionuclides $\left(10^{-8}-10^{-9} \mathrm{M}\right)$ implies the appearance of a large excess of metal-binding sites over the number of metal cations. Therefore, it seems justified to propose the monolayer coverage of the surface.

\section{Comparison of the radionuclide sorption in the optimum conditions}

Comparison of the spherical calcium, strontium and barium alginates as potential sorbents for the removal of $\mathrm{Cs}^{+}, \mathrm{Sr}^{2+}$ and $\mathrm{Am}^{3+}$ radionuclides from the dilute $\left(10^{-8}-10^{-9} \mathrm{M}\right)$ aqueous solutions is presented in Fig. 4. It can be seen that logarithms of the partition constants $\left(\log K_{d}\right)$ between the solid and liquid phases for $\mathrm{Am}^{3+}$ and $\mathrm{Sr}^{2+}$ cations vary between 3 and 4.5. In turn, the $\mathrm{Cs}^{+}$cation is much less sorbed, and the $K_{d}$ values are one or two orders lower. Such poor sorption of monovalent cations may probably be a result of the solubility of the alkali metal alginates in water.

The values of the partition coefficients shown in Fig. 4 for each radionuclide do not significantly depend on the alginate gelling metal (calcium, strontium or barium). Such weak dependence has already been confirmed for the magnetic alginates [3].

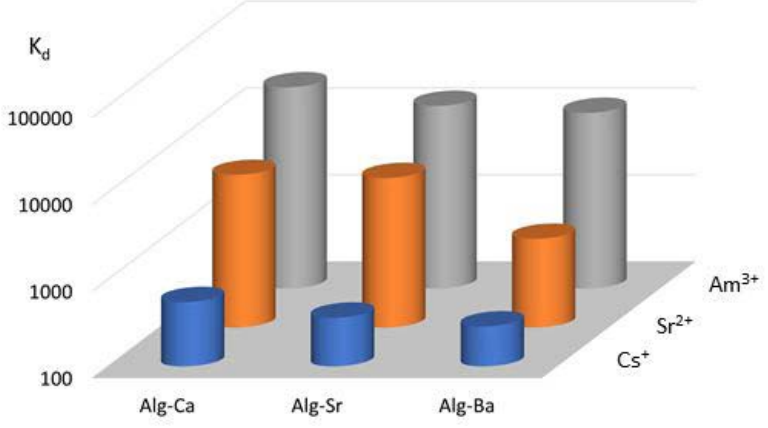

Fig. 4. Comparison of the adsorption of micro amounts $\left(10^{-9} \mathrm{M}\right)$ of the radionuclides onto calcium, strontium and barium alginate biosorbents (room temperature, $\mathrm{pH} 5$, contact time of the phases: $300 \mathrm{~min}$ ).
Table 2. The desorption percentage of $\mathrm{Cs}^{+}, \mathrm{Sr}^{2+}$ and $\mathrm{Am}^{3+}$ from the alginates studied. Standard deviation in the population of each determination: about $\pm 0.1 \%$

\begin{tabular}{|c|c|c|c|c|c|}
\hline & $\mathrm{H}_{2} \mathrm{O}$ & $\mathrm{HCl}$ & $\mathrm{NaNO}_{3}$ & $\mathrm{NaHCO}_{3}$ & $\mathrm{Na}_{2} \mathrm{SO}_{4}$ \\
\hline \multicolumn{6}{|c|}{ Calcium alginate } \\
\hline $\mathrm{Am}^{3+}$ & $1.6 \%$ & $4.4 \%$ & $0.9 \%$ & $7.8 \%$ & $8.7 \%$ \\
\hline $\mathrm{Sr}^{2+}$ & $5.5 \%$ & $12.5 \%$ & $8.8 \%$ & $9.9 \%$ & $5.5 \%$ \\
\hline $\mathrm{Cs}^{+}$ & $2.2 \%$ & $2.2 \%$ & $2.2 \%$ & $2.2 \%$ & $2.2 \%$ \\
\hline \multicolumn{6}{|c|}{ Strontium alginate } \\
\hline $\mathrm{Am}^{3+}$ & $0.8 \%$ & $1.0 \%$ & $3.3 \%$ & $7.3 \%$ & $10.8 \%$ \\
\hline $\mathrm{Sr}^{2+}$ & $6.1 \%$ & $15.8 \%$ & $15.8 \%$ & $30.4 \%$ & $25.5 \%$ \\
\hline $\mathrm{Cs}^{+}$ & $2.4 \%$ & $2.4 \%$ & $2.4 \%$ & $2.4 \%$ & $2.4 \%$ \\
\hline \multicolumn{6}{|c|}{ Barium alginate } \\
\hline $\mathrm{Am}^{3+}$ & $0.5 \%$ & $1.6 \%$ & $2.0 \%$ & $7.6 \%$ & $8.9 \%$ \\
\hline $\mathrm{Sr}^{2+}$ & $8.3 \%$ & $25.0 \%$ & $17.6 \%$ & $15.9 \%$ & $7.3 \%$ \\
\hline $\mathrm{Cs}^{+}$ & $2.4 \%$ & $2.4 \%$ & $2.4 \%$ & $2.4 \%$ & $2.4 \%$ \\
\hline
\end{tabular}

\section{Desorption of the radionuclides}

The desorption results obtained are shown in Table 2. Quantitatively, they are expressed in terms of the desorption percentage, i.e., the percent of radionuclides leached from the saturated sorbent.

The results obtained permit the following conclusions to be drawn:

- For all alginates, solutions of $0.01 \mathrm{M} \mathrm{NaHCO}_{3}$ and $0.01 \mathrm{M} \mathrm{Na}_{2} \mathrm{SO}_{4}$ desorb $\mathrm{Am}^{3+}$ most effectively. The most favourable desorption solution for $\mathrm{Sr}^{2+}$ is $0.01 \mathrm{M} \mathrm{HCl}$, while no significant $\mathrm{Cs}^{+}$desorption is observed in any of the tested solutions.

- When comparing desorption from barium, strontium and calcium alginates, it can be seen that $\mathrm{Am}^{3+}$ may be desorbed from all three sorbents in comparable amounts, while $\mathrm{Sr}^{2+}$ and $\mathrm{Cs}^{+}$desorb from barium and strontium alginates in similar quantities, and show the greatest desorption from calcium alginate.

\section{Conclusions}

The biosorption of $\mathrm{Cs}^{+}, \mathrm{Sr}^{2+}$ and $\mathrm{Am}^{3+}$ ions by three alkaline earth alginates was studied in a batch system as a function of the initial $\mathrm{pH}$ of the aqueous solution, contact time of the phases and the radionuclide content in the purified solution. The $\mathrm{pH}$ slightly affects the uptake of metal ions; however, the optimum initial $\mathrm{pH}$ of the solution was found to be 5-6 for all systems studied. The optimum equilibration time of the solution was established as $120 \mathrm{~min}$ with calcium alginate and 180 min with strontium and barium alginates. The Freundlich isotherm was found to be the best fit for the obtained sorption results, which means that the surface of the sorbent is heterogeneous, due to irregularly distributed mannuronic and glucuronic units. Only the latter are involved in the metal bonding process. The great dilution of the radionuclides $\left(10^{-8}-10^{-9} \mathrm{M}\right)$ suggests a monolayer coverage of the surface.

Different desorbing solutions were tested for the alginate sorbents loaded with the radionuclides, and 
no systematics were found in the desorption of the radionuclides.

Acknowledgments. This work has been performed in part as the PhD thesis of Dr. Agata Oszczak-Nowińska and the statutory studies of the Institute of Nuclear Chemistry and Technology.

Conflict of interest. The authors declare that there is no conflict of interest in the presented work.

\section{ORCID}

L. Fuks (D) http://orcid.org/0000-0002-2178-1366

\section{References}

1. Naja, G. M., \& Volesky, B. (2009). Treatment of metal-bearing effluents: removal and recovery. Boca Raton, FL: Taylor \& Francis and CRC Press.

2. Ahmad, W. A., Jaapar, J., \& Mior Ahmad, K. M. Z. (2004). Removal of heavy metals from wastewater. In A. Pandey (Ed.), Concise encyclopedia of bioresource technology (pp. 152-157). New York: The Haworth Press Inc.

3. President of the Republic of Poland. (2006). Ustawa o biokomponentach i biopaliwach ciekłych (Act on biocomponents and liquid biofuels. Dz. U. (Journal of Laws), 169, item 1199. (in Polish).

4. Fuks, L., Herdzik-Koniecko, I., Polkowska-Motrenko, H., \& Oszczak, A. (2018). Novel procedure for removal of the radioactive metals from aqueous wastes by the magnetic calcium alginate. Int. J. Environ. Sci. Technol., 8, 1-12.
5. Fuks, L. (2018). Improvement of the novel method for decontamination of the radioactive aqueous solutions. Environ. Technol. Innov., 12, 286-292.

6. Fuks, L., Oszczak, A., Gniazdowska, E., \& Sternik, D. (2014). Calcium alginate and chitosan as potential sorbents for strontium radionuclide. J. Radioanal. Nucl. Chem., 304(1), 15-20.

7. Banerjee, A., \& Nayak, D. (2007). Biosorption of nocarrier-added radionuclides by calcium alginate beads using 'tracer packet' technique. Bioresour. Technol., 98, 2771-2774.

8. Dang, T. T. H., Li, C. -W., \& Choo, K. -H. (2016). Comparison of low-pressure reverse osmosis filtration and polyelectrolyte-enhanced ultrafiltration for the removal of Co and Sr from nuclear plant wastewater. Sep. Purif. Technol., 157, 209-214.

9. Liu, X., Chen, G. -R., Lee, D. -J., Kawamoto, T., Tanaka, H., Chen, M. -L., \& Luo, Y. -K. (2014). Adsorption removal of caesium from drinking waters: A mini review on use of biosorbents and other adsorbents. Bioresour. Technol., 160, 142-149.

10. National Atomic Energy Agency (PAA). (2017). National Report of Republic of Poland on compliance with obligations of the Joint Convention on the Safety of Spent Fuel Management and on the Safety of Radioactive Waste Management. Available from https:// www.iaea.org/sites/default/files/national_report_of_ poland for the 6 th review meeting - english.pdf.

11. KTH Royal Institute of Technology. (2020). Medusa KTH Programme. Stockholm, Sweden: Royal Institute of Technology. https://www.kth.se/che/medusa/ downloads-1.386254 (last accessed: 20.12.2020).

12. Foo, K. Y., \& Hameed, B. H. (2010). Insights into the modeling of adsorption isotherm systems. Chem. Eng. J., 156(1), 2-10. DOI: 10.1016/j.cej.2009.09.013.

13. Ayawei, N., Ebelegi, A. N., \& Wankasi, D. (2017). Modelling and interpretation of adsorption isotherms. J. Chem., 2017, 1-11. 